\title{
The Cancer Microenvironment: Mechanical Challenges of the Metastatic Cascade
}

\author{
Sebastian E. Amos and Yu Suk Choi* \\ School of Human Sciences, The University of Western Australia, Perth, WA, Australia
}

The metastatic cascade presents a significant challenge to patient survival in the fight against cancer. As metastatic cells disseminate and colonize a secondary site, stepwise exposure to microenvironment-specific mechanical stimuli influences and protects successful metastasis. Following cancerous transformation and associated cell recruitment, the tumor microenvironment (TME) becomes a mechanically complex niche, owing to changes in extracellular matrix (ECM) stiffness and architecture. The ECM mechanically reprograms the cancer cell phenotype, priming cells for invasion. 2D

OPEN ACCESS

Edited by:

Elisabetta Ada Cavalcanti-Adam, Max-Planck-Gesellschaft (MPG),

Germany

Reviewed by:

Philipp Seib,

University of Strathclyde,

United Kingdom

Honglin Jin,

Huazhong University of Science and Technology, China

*Correspondence:

Yu Suk Choi

yusuk.choi@uwa.edu.au

Specialty section:

This article was submitted to

Biomaterials,

a section of the journal

Frontiers in Bioengineering and

Biotechnology

Received: 04 November 2020

Accepted: 18 January 2021

Published: 12 February 2021

Citation:

Amos SE and Choi YS (2021) The

Cancer Microenvironment:

Mechanical Challenges of the

Metastatic Cascade.

Front. Bioeng. Biotechnol. 9:625859.

doi: 10.3389/fbioe.2021.625859 and 3D hydrogel-based culture platforms approximate these environmental variables and permit investigations into tumor-dependent shifts in malignancy. Following TME modification, malignant cells must invade the local ECM, driven toward blood, and lymph vessels by sensing biochemical and biophysical gradients. Microfluidic chips recreate cancer-modified ECM tracks, empowering studies into modes of confined motility. Intravasation and extravasation consist of complex cancer-endothelial interactions that modify an otherwise submicron-scale migration. Perfused microfluidic platforms facilitate the physiological culture of endothelial cells and thus enhance the translatability of basic research into metastatic transendothelial migration. These platforms also shed light on the poorly understood circulating tumor cell, which defies adherent cell norms by surviving the shear stress of blood flow and avoiding anoikis. Metastatic cancers possess the plasticity to adapt to new mechanical conditions, permitting their invasiveness, and ensuring their survival against anomalous stimuli. Here, we review the cellular mechanics of metastasis in the context of current in vitro approaches. Advances that further expose the mechanisms underpinning the phenotypic fluidity of metastatic cancers remain central to the development of novel interventions targeting cancer.

Keywords: extracellular matrix, confinement, mechanotransduction, invasion, biophysics, stiffness

\section{INTRODUCTION}

Cancer remains a leading cause of death globally; a burden largely attributed to cancer cell metastasis (World Health Organisation, 2018). While the genetic and biochemical drivers of metastasis are widely recognized, biophysical stimuli also progress cancer. Like all other cell types, cancerous cells perceive physical inputs from their microenvironment that mechanically alter DNA transcription and, thus, cell behavior and function, a process known as mechanotransduction (Eyckmans et al., 2011; Broders-Bondon et al., 2018). Such stimuli include the stiffness, 
composition, and architecture of the extracellular matrix (ECM), the mechanotransduction of which enhances and protects successful metastasis (Wei et al., 2015). All stages of the metastatic cascade are inherently mechanical, as cells invade through and interact with tissues and fluids of varying compositions and rheological properties. While these stimuli are implicated in malignancy, their contributions remain incompletely understood. Our ability to study metastatic mechanics in vitro is dependent on microfluidics and biomimetic substrates. Ongoing developments in these platforms continue to refine in vitro investigations of the cancer-microenvironment interface. Here, we review key biophysical mechanics of the metastatic cascade and our ability to study them in vitro to further our understandings of this complex disease.

\section{THE TUMOR MICROENVIRONMENT}

Cancerous transformation inflames the surrounding tissue and activates cancer-associated cell types, prompting the pathogenesis of the tumor microenvironment (TME) (Hanahan and Weinberg, 2011; Kim and Bae, 2016; Yamauchi et al., 2020). This is characterized by the upregulated deposition, reorganization, and increased crosslinking of ECM proteins, such as fibronectin and collagen type I (Tschumperlin and Lagares, 2020). This disruption of ECM homeostasis alters matrix deformability and ligand availability, thus perturbing local cell mechanotransduction. Moreover, increased ECM deposition and crosslinking compartmentalizes and compresses the tumor as its diverse cellular population proliferates (Tse et al., 2012; Vennin et al., 2018). The destabilized mechanical and biochemical profiles of the TME coalesce to drive pre-metastatic phenomena, such as epithelial-mesenchymal plasticity (EMP) (Redfern et al., 2019). In isolating TME mechanics' effect on tumor progression and metastasis, investigators employ a combination of 2D and 3D hydrogel-based cell culture systems. The stiffness, composition, and pore size of the ECM can be highly controlled and manipulated within such hydrogel platforms, granting control over the important haptotactic and durotactic stimuli that drive metastasis (Table 1).

\section{Extracellular Matrix Stiffness}

Perhaps one of the most well documented solid TME characteristics is associated ECM stiffening. While this is downstream of initial tumorigenesis, owing to the recruitment and activation of cancer-associated fibroblasts, there is an established link between ECM stiffening and metastasis. 2D and 3D (encapsulating) hydrogel platforms (such as collagen, gelatin, or alginate-based gels) find that increased ECM stiffness drives invasion in metastatic breast cancer cells, while non-cancerous cells did not exhibit such invasive phenotypes (Levental et al., 2009; Chaudhuri et al., 2014; Peela et al., 2016; Ondeck et al., 2019). This may owe to oncogene-mediated changes in mechanosensitivity, which alters the transduction of ECM stiffening (Panciera et al., 2020). While this mechanoperception, at least in part, utilizes established mechanosensitive transcriptional regulators
YAP/TAZ, 3D encapsulation reduces cross-sectional force exposure, suggesting metastatic mechanosensation may operate through parallel, YAP-independent pathways (Lee et al., 2019). This reprogramming of mechanosensation further enhances phenotypic plasticity, whereby the viscoelasticity of metastatic cells is dynamic and environmentally impressionable compared to their non-metastatic counterparts (Tian et al., 2020). Interestingly, stiffness-dependent chemoresistance is also observed in $2 \mathrm{D}$ and $3 \mathrm{D}$ hydrogel platforms (Rice et al., 2017; Joyce et al., 2018). Moreover, this stiffnessmediated resistance was only observed in metastatic cell lines, suggesting that phenotypic plasticity and prosurvival activation in metastatic cancer cells are both mechanically coupled.

\section{Extracellular Matrix Architecture}

In addition to stiffening, cancer-associated ECM is more dense and aligned, forming ECM highways for invading cells and altering ligand spacing within and around the tumor. Changes in ligand availability alter integrin subunit involvement, clustering, and focal adhesion complex assembly, thus perturbing intracellular signaling cascades that influence cell behaviors, including migration, proliferation, and survival (Figure 1A; Levental et al., 2009; Jang and Beningo, 2019). As such, when interacting with a sparse, non-cancerous ECM, the invasive and proliferative tendencies of readily metastatic cells are suppressed, suggestive of a liganddependent reprogramming that is maintained with a change in microenvironment (Kaukonen et al., 2016). While normal and cancerous fibroblast-generated matrices demonstrate the importance of ligand density, these techniques cannot be well controlled, nor their variables (such as compounded stiffness) isolated. The advent of 2D nano-spaced ligand platforms permits the investigation of ECM density with single-cell resolution. Studies find that cancer cell morphology, motility, plasticity, and adhesion are manipulated in a ligand densitydependent manner (Lee et al., 2011; Amschler et al., 2014, 2018; Horzum et al., 2015). Interestingly, varying ligand density demonstrates a proportional exchange between cell-cell and cell-ECM adhesion (Horzum et al., 2015). Moreover, cells on controlled ligand spacing platforms have also exhibited shifts in states of EMP, implicating ECM density in metastatic progression (Marlar et al., 2016). These nano-spaced ligand platforms have recently been combined with blocking peptidomimetics to delineate integrin subtype involvement in breast cancer drug resistance. Young et al. (2020) demonstrated that metastatic breast cancer drug sensitivity was highly dependent on ligand spacing and integrin subtype, thus affirming ECM architecture's influence on metastatic protection and progression. Finally, regarding in vitro models of the TME, the importance of co-culture platforms, through which ECM, phenotypic, and chemoreceptive norms are modified by accessory cell types, such as cancer-associated fibroblasts and macrophages, must also be acknowledged (Kuen et al., 2017; Plaster et al., 2019; Vennin et al., 2019; Huang et al., 2020; Libring et al., 2020; Lugo-Cintrón et al., 2020). 
TABLE 1 | The advantages and disadvantages of selected platforms to study the mechanics of the metastatic cascade.

\begin{tabular}{|c|c|c|c|c|c|}
\hline $\begin{array}{l}\text { Metastatic } \\
\text { cascade }\end{array}$ & Platform & Description & Advantages & Disadvantages & Key papers \\
\hline \multirow[t]{2}{*}{$\begin{array}{l}\text { Tumor } \\
\text { Microenvironment }\end{array}$} & $\begin{array}{l}\text { 2D } \\
\text { Nano-spacing }\end{array}$ & $\begin{array}{l}\text { Block copolymer micelle nanolithography (BCMN) } \\
\text { and peptidomimetics are used to synthesize } \\
\text { nano-spaced peptide-coated particles on a culture } \\
\text { substrate }\end{array}$ & $\begin{array}{l}\text { ECM ligand density can be } \\
\text { highly controlled } \\
\text { Single-cell resolution }\end{array}$ & $\begin{array}{l}\text { 2D cultures do not recreate 3D in vivo cell-cell } \\
\text { and cell-ECM interactions }\end{array}$ & $\begin{array}{l}\text { Young et al., } 2020 \\
\text { Amschler et al., } 2018\end{array}$ \\
\hline & 3D Hydrogels & $\begin{array}{l}\text { Tuneable semi-synthetic hydrogels such as GelMA } \\
\text { and alginate-based interpenetrating networks utilize } \\
\text { UV or } \mathrm{Ca}^{2+} \text { crosslinking to modulate substrate } \\
\text { stiffness (and pore size in GelMA) }\end{array}$ & $\begin{array}{l}\text { Replicates cell-cell and } \\
\text { cell-ECM interactions } \\
\text { On-demand (temporally } \\
\text { and spatially) tuneable } \\
\text { stiffness/pore size } \\
\text { Elastic and viscoelastic } \\
\text { options }\end{array}$ & $\begin{array}{l}\text { Reduced imaging quality/ease of imaging with } \\
\text { increasing sample thickness } \\
\text { Unable to replicate the diversity of natural ECM }\end{array}$ & $\begin{array}{l}\text { Panciera et al., } 2020 \\
\text { Joyce et al., } 2018 \\
\text { Kim C. et al., } 2020 \\
\text { Peela et al., } 2016\end{array}$ \\
\hline \multirow[t]{2}{*}{ Invasion } & 3D Hydrogels & $\begin{array}{l}\text { Tuneable natural hydrogels such as collagen type I } \\
\text { or reconstituted basement membrane are thermally } \\
\text { polymerized. Substrate stiffness can be controlled } \\
\text { by adjusting protein concentration and gelation } \\
\text { temperature }\end{array}$ & $\begin{array}{l}\text { Tuneable soft stiffness's } \\
\text { Native ECM proteins } \\
\text { Viscoelastic properties } \\
\text { close to in vivo conditions }\end{array}$ & $\begin{array}{l}\text { Tuneable stiffness typically does not cover the } \\
\text { complete physiological range } \\
\text { Cannot control pore size }\end{array}$ & $\begin{array}{l}\text { Chaudhuri et al., } 2014 \\
\text { Wullkopf et al., } 2018\end{array}$ \\
\hline & Microchannels & $\begin{array}{l}\text { Soft lithography is used to fabricate microchannels } \\
\text { of varying dimensions and topographies by casting } \\
\text { polydimethylsiloxane over silicon wafers/molds }\end{array}$ & $\begin{array}{l}\text { High spatial resolution } \\
\text { Relatively cheap } \\
\text { Routine microscopy } \\
\text { compatible }\end{array}$ & $\begin{array}{l}\text { Reduced substrate stiffness tuneability } \\
\text { Unable to recreate true heterogeneity of tissue } \\
\text { topography }\end{array}$ & $\begin{array}{l}\text { Holle et al., } 2019 \\
\text { Ma et al., } 2018 \\
\text { Microchannels created in } \\
\text { collagen address this, see } \\
\text { Mosier et al., } 2019\end{array}$ \\
\hline \multirow[t]{2}{*}{ Intra/Extravasation } & $\begin{array}{l}\text { Co-culture } \\
\text { Microfluidics }\end{array}$ & $\begin{array}{l}\text { Soft lithography is used to fabricate perfused } \\
\text { microfluidic chips designed to accommodate } \\
\text { different cells types that can communicate and } \\
\text { interact through media or hydrogel reservoirs }\end{array}$ & $\begin{array}{l}\text { Physiological culture of } \\
\text { endothelial cells in } \\
\text { platforms with flow } \\
\text { Inter-cellular } \\
\text { communication }\end{array}$ & $\begin{array}{l}\text { Increased cost, preparation time, and resource } \\
\text { demand } \\
\text { Reduced data resolution with increasing } \\
\text { complexity }\end{array}$ & $\begin{array}{l}\text { Chen et al., } 2013 \\
\text { Nguyen et al., } 2019\end{array}$ \\
\hline & $\begin{array}{l}\text { Subnuclear } \\
\text { Microchannels }\end{array}$ & $\begin{array}{l}\text { Soft lithography or glass etching allows for the } \\
\text { fabrication of subnuclear constriction challenges. } \\
\text { Nuclear constriction topographies include periodic } \\
\text { pinch-points and restricted channels }\end{array}$ & $\begin{array}{l}\text { Highly controlled } \\
\text { constriction dimensions } \\
\text { Single-cell resolution with } \\
\text { manipulability }\end{array}$ & $\begin{array}{l}\text { Limited control of perceived substrate stiffness } \\
\text { Increased preparation time and required } \\
\text { resources }\end{array}$ & $\begin{array}{l}\text { Raab et al., } 2016 \\
\text { Sima et al., } 2020\end{array}$ \\
\hline \multirow[t]{2}{*}{$\begin{array}{l}\text { Circulating } \\
\text { Tumor Cells }\end{array}$} & Microfluidics & $\begin{array}{l}\text { Soft lithography-fabricated microfluidic chips are } \\
\text { connected to pumps that circulate cell media and } \\
\text { thus exert shear stresses on cells and/or maintain } \\
\text { them in suspended culture }\end{array}$ & $\begin{array}{l}\text { Application and control of } \\
\text { fluidic shear stress } \\
\text { Reduced handling during } \\
\text { experimentation }\end{array}$ & $\begin{array}{l}\text { Lacking interaction with native blood/lymph } \\
\text { cells } \\
\text { Live-cell imaging resources } \\
\text { Increased preparation time }\end{array}$ & $\begin{array}{l}\text { Zhang et al., } 2014 \\
\text { Fan et al., } 2016 \\
\text { Can be utilized for real-time } \\
\text { deformability cytometry see } \\
\text { Otto et al., } 2015\end{array}$ \\
\hline & $\begin{array}{l}\text { Metastasis-on- } \\
\text { a-chip }\end{array}$ & $\begin{array}{l}\text { Composite platforms incorporating a combination } \\
\text { of the above platforms (i.e., 3D encapsulated cell } \\
\text { types and perfused microfluidics) to study the } \\
\text { metastatic cascade in an integrated fashion }\end{array}$ & $\begin{array}{l}\text { Incorporation of many } \\
\text { in vivo variables } \\
\text { Multi-system chip scalability }\end{array}$ & $\begin{array}{l}\text { Reduced data resolution with increasing } \\
\text { complexity } \\
\text { Optimizing culture media } \\
\text { Increased preparation time and required } \\
\text { resources } \\
\text { Low through-put }\end{array}$ & $\begin{array}{l}\text { Rajan et al., 2020b } \\
\text { Aleman and Skardal, } 2019 \\
\text { Hassell et al., } 2017\end{array}$ \\
\hline
\end{tabular}

Soft lithography is used to fabricate microchannels of varying dimensions and topographies by casting

Soft lithography is used to fabricate perfused microfluidic chips designed to accommodate different cells types that can communicate and interact through media or hydrogel reservoirs

Composite platforms incorporating a combination

of the above platforms (i.e., 3D encapsulated cell

types and perfused microfluidics) to study the

in vivo variables

Multi-system chip scalability 


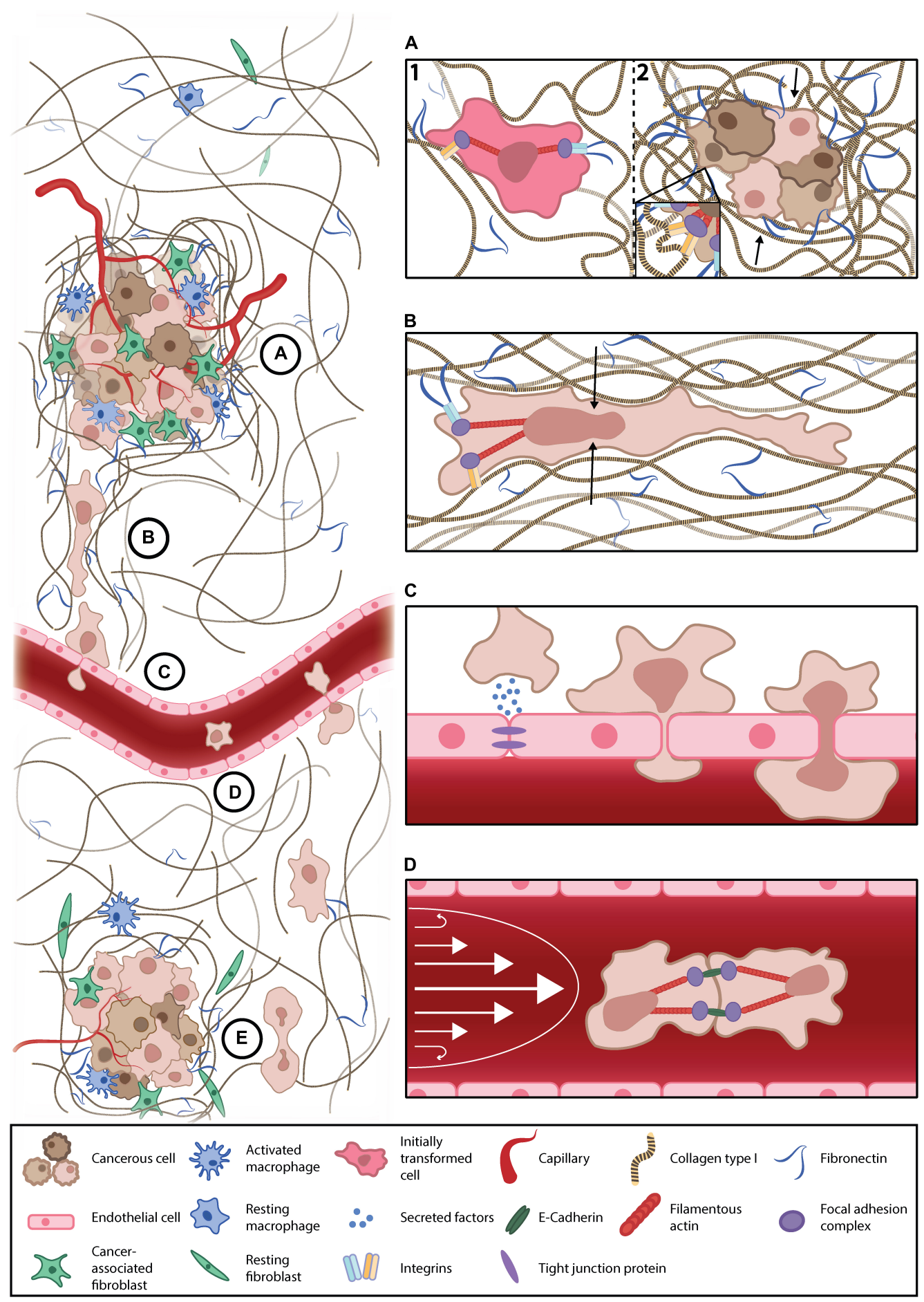

FIGURE 1 | Key mechanical forces of the metastatic microenvironment. (A) Cancer-associated remodeling of the normal extracellular matrix (ECM) (1) increases local stiffness and alters ligand availability in and around the tumor microenvironment (TME), the mechanotransduction of which enhances cancer cell survival, proliferation, and primes cells for metastasis (2). (B) Invasive cells escape the primary tumor through confined, subnuclear ECM tracks. Such confinement deforms the nucleus (black arrows) and reprograms anchorage dependency, thereby altering transcriptional regulator translocation, conventional mechanotransduction pathways, and, thus, the invasive phenotype. (C) Current understandings of transendothelial migration suggest interacting cancer cells mechanically and chemically modify these submicron constrictions with permeabilizing factors and cancer-associated inflammation of the endothelium. (D) Cancer cells must survive anoikis while disseminating in the blood/lymph. They may evade anoikis by clustering to engage cell-cell adhesions that generate intracellular tension that is transduced to the nucleus, replacing the lost input of substrate adhesion, thereby suppressing anchorage-dependent apoptosis. Moreover, suspended cancer cells (or circulating tumor cells) must survive the shear stress of blood flow (white arrows). (E) Upon reaching a distant secondary site, metastatic cells must survive in a foreign environment, the mechanical and chemical profiles of which differ from their tissue of origin. 


\section{INVASION IN THE LOCAL MICROENVIRONMENT}

To escape the TME, disseminating cells must invade toward intra- or extra-tumoral blood and lymph vessels (Nguyen et al., 2009). ECM crosslinking and the consequently decreased pore size and rate-limiting factors such as nuclear size and integrity mechanically govern cancer cell invasion (Wisdom et al., 2018). Tumor-modified ECM tracks are narrower than 5 microns in some instances, presenting invasive cells with prolonged and repeated constriction challenges (Weigelin et al., 2012). Such confinement differentially influences an invading cell's motility and resilience, depending on their metastatic competence, which owes to TME reprogramming (Bhatia et al., 2020). Polydimethylsiloxane (PDMS)-cast microchannel devices permit the mimicry of narrowed ECM pores/tracks with precisely controlled channel dimensions. These platforms endeavor to highlight confinement-dependent changes in metastatic patterns of locomotion.

\section{Mechanical Confinement Enhances Cancer Invasion}

Recent studies demonstrate that cancer invasion speed increases with the degree of constriction in long, representative microtracks (Holle et al., 2019; Mosier et al., 2019; Wang et al., 2019). Interestingly, invasion speed also increases with the number of brief, periodic constriction challenges (Mak et al., 2013; Ma et al., 2018). These studies observe confinementdependent motility changes, with some reporting a mesenchymal to amoeboid-type shift in locomotion, owing to an adhesionindependent reprogramming, as is observed in immune cell invasion (Reversat et al., 2020). This reprogrammed adhesion has been recently highlighted and is accompanied by cell softening consistent with decreases in force exertion on the surrounding ECM (Guck et al., 2005; Kristal-Muscal et al., 2013; Khan et al., 2018; Holenstein et al., 2019; Beri et al., 2020; Han et al., 2020). Importantly, these mechanical traits of an amoeboid phenotype are evident in patient samples (Swaminathan et al., 2011; Plodinec et al., 2012). These data assert an amoeboid transition under confinement as a distinct paradigm during cancer invasion that traditional models of epithelial-mesenchymal transition are unable to characterize.

Nuclear membranes are coupled to the ECM through cytoskeletal fibers in established mechanotransduction pathways (Holle et al., 2018). In amoeboid-transformed cells, reduced ECM coupling obscures classical models of mechanotransduction. However, mechanically gated nuclear pores stretch during nuclear deformation, promoting the shuttling of transcriptional regulators, and activating signaling cascades that modify cell migration and behavior (Elosegui-Artola et al., 2017; Venturini et al., 2020). Under extreme constriction, the nuclear envelope ruptures, resulting in the mixing of the cytosolic, and nuclear contents; a phenomenon that does not impede cancer invasion (Denais et al., 2016; Raab et al., 2016). Interestingly, metastatic cells become more invasive following nuclear envelope rupture, whereas non-cancerous cells undergo accelerated senescence
(Nader et al., 2020). Therefore, a deformed or repeatedly ruptured nucleus under confinement may become an independently mechanosensitive apparatus responsible for guiding cell behavior during cancer invasion (Figure 1B). However, the role of such nuclear mechanics in cancer invasion remains a current topic of interest (Fu et al., 2012; Kirby and Lammerding, 2018; Mierke, 2019; Heo et al., 2020; Herráez-Aguilar et al., 2020; Lomakin et al., 2020).

\section{INTRAVASATION AND EXTRAVASATION}

The reprogramming of invasive cells into less matrix-dependent, amoeboid-like cells demonstrates the phenotypic plasticity of metastatic cells but likely functions in preparing invading cells for the extreme confinement encountered during intravasation and extravasation (Chiang et al., 2016). Upon reaching an intra- or extra-tumoral vessel, invasive cells must traverse the endothelial barrier, which is bound by submicron-scale cellcell adhesions, including tight junctions (Wallez and Huber, 2008). Invasive cancer cells and associated cell types, such as macrophages, may modify these junctions to reduce the degree of confinement experienced, although these mechanisms are not fully known (Zervantonakis et al., 2012). Researchers integrate microfluidic PDMS devices with biomimetic substrates (hydrogels) and multicellular co-cultures to interrogate cancerendothelial mechanics. Similar to studies of invasion, the extreme confinement of trans-endothelial migration can be approximated using advanced microfabrication techniques.

\section{Microfluidic Co-culture Platforms Reveal Complex Cancer-Vessel Interactions}

Perfused microfluidic devices recreate one of the most formidable mechanical stresses of the metastatic cascade, fluidic shear stress. These platforms facilitate the physiological culture of endothelial cells, the permeability, and morphology of which are mechanically regulated by flow, thus, improving research translatability of endothelial traversal or junction modification (Wang et al., 2013; Sfriso et al., 2018). Perfused platforms demonstrate that both flow rate and pulsatility influence cancerendothelial adhesion and subsequent traversal (Kühlbach et al., 2018). Furthermore, trans-endothelial migration is cooperated by disruptions in endothelial permeability owing to external mechanical and chemical perturbation; as is observed in cancerassociated macrophage activation or exposure to tissue-specific factors (Figure 1C; Jeon et al., 2013, 2015; Lee et al., 2014; Peng et al., 2019; Zavyalova et al., 2019). Not all cancer cells possess the ability to traverse the endothelium, which may reflect the phenotypic heterogeneity of metastatic cells (Jeon et al., 2013; Bertulli et al., 2018). Interestingly, mechanically resilient amoeboid phenotypes have been observed during intravasation, evidenced by macrophage-mediated RhoA activity (Kosla et al., 2013; Roh-Johnson et al., 2014). An important study by Chen et al. (2013) demonstrates the endothelium's pliability as a mechanical barrier, visualizing increases in endothelial apertures throughout a single extravasation. They also report clusters of extravasating cells, which may increase local endothelial 
exposure to permeabilizing, proinflammatory cancer secretions, further destabilizing the endothelium and enhancing metastatic progression (Chen et al., 2013). In platforms that lack perfusion, metastatic cells still perturb the endothelium's structural integrity to facilitate intravasation, findings that are supported in vivo (Nguyen et al., 2019).

While co-culture studies more accurately recapitulate cancerendothelial interactions, they make it challenging to isolate the submicron constriction mechanics that may constitute intra- and extravasation. Recently, glass microfluidic devices with submicron constriction challenges were fabricated with femtosecond laser-assisted etching. While this platform does not recreate other essential variables, such as ECM stiffness, it demonstrates that metastatic cells are capable of submicron invasion and that, as previously reported, invasion speeds increase with constriction. Crucially, this mechanical challenge did not impair post-constriction proliferation or migration (Sima et al., 2020).

\section{SURVIVING IN SUSPENSION}

Cancer cells can escape many forms of programmed cell death through a myriad of signaling cascades, some of which are mechanically coupled (Hanahan and Weinberg, 2011). Once invading cells have successfully intravasated, they must survive hemodynamic shear stresses and escape anchoragedependent apoptosis, known as anoikis (Paoli et al., 2013). In suspension, an adherent cell should undergo anoikis owing to the loss of integrin-mediated apoptotic suppression, as is observed in normal epithelial turnover (Frisch and Screaton, 2001; Paoli et al., 2013). Nevertheless, a suspended cancer cell can withstand this loss of mechanical signaling and disseminate as a circulating tumor cell (CTC). The mechanisms through which CTCs evade anoikis are conflicting, but have been recently eluded to in studies employing microfluidic systems. As with studies of intra- and extravasation, perfused microfluidic devices provide an approximated physiological mimic within which the behaviors of CTCs may be investigated. Combining these perfused devices, with conditioned CTCs and other, hydrogelembedded cell types grants an unprecedented look at the metastatic cascade in its entirety; an emerging study tool known as metastasis-on-a-chip.

\section{Circulating Tumor Cells}

Circulating tumor cells form multicellular clusters in vitro and in vivo (Chen et al., 2013; Yu et al., 2013; Aceto et al., 2014; Au et al., 2016). This cell-cell adhesion, and subsequent engagement of adherens junction proteins, such as cadherin, initiates mechanically coupled antiapoptotic signaling cascades and thus, afford CTCs time to disseminate in suspension (Guadamillas et al., 2011; Li et al., 2019; Tang et al., 2020). Studies demonstrate that the mechanotransduction of shear stress may facilitate this phenotypic shift (Zhao et al., 2014; Yang et al., 2016; Follain et al., 2020). Moreover, cancer cells exposed to physiological shear stress are more invasive, proliferative, and chemoresistant than non-cancerous cells and CTCs in static conditions
(Lee et al., 2017, 2018; Novak et al., 2019). Therefore, not only are CTCs resistant to anoikis and physiological shear stresses, but such stimuli potentiate metastasis (Figure 1D; Barnes et al., 2012; Zhang et al., 2018). CTC clusters remain highly deformable while maintaining cell-cell adhesions, permitting the navigation of capillary-sized constrictions (Au et al., 2016). Shear stress also enhances extravasation and migration in CTCs, owing to increases in cellular oxidative stress (Ma et al., 2017). Interestingly, while initially softer, metastatic cells stiffen following shear stress exposure, while their non-cancerous counterparts were unresponsive. This reinforces an oncogenemediated reprogramming of cellular mechanosensitivity and cytoskeletal mechanoadaptation (Chivukula et al., 2015).

\section{Metastasis-on-a-Chip}

Throughout the metastatic cascade, one mechanical exposure seemingly prepares the invading cell for the next. Logically, this progression should be studied in an integrated fashion, rather than in isolation, as is traditional of reductionist research. As such, some metastasis-on-a-chip platforms allow researchers to study each stage of the metastatic cascade in a single microfluidic device (Sleeboom et al., 2018; Sontheimer-Phelps et al., 2019). These facilitate investigations into metastatic enigmata, like organotropism, whereby metastasizing cells have a secondary tissue preference (Figure 1E; Hoshino et al., 2015). While in its infancy, organotropic studies of metastasis do elude to disseminative preference and demonstrate stiffness-dependent TME escape, reflecting in vivo observations (Skardal et al., 2016; Aleman and Skardal, 2019). While cellular mechanics become difficult to resolve with increasing system complexity, important physical cues may be reproduced, and their effects on cancer progression, examined; such as the cyclic tension of respiration in a model of lung metastasis (Hassell et al., 2017). Such biomimetic systems also lend themselves to pharmacological and biochemical screening, granting researchers insight into how such conditioning modifies and influences the biophysics of metastatic microenvironments (Kim J. et al., 2020; Nashimoto et al., 2020; Palacio-Castaneda et al., 2020; Rajan et al., 2020a,b; Sharifi et al., 2020).

\section{CONCLUSION AND FUTURE PERSPECTIVES}

Recent research establishes the stepwise biophysical cues of the metastatic cascade as essential drivers of malignancy. Each step of the metastatic cascade presents an opportunity to perturb cancer's mechanically coupled progression. Unfortunately, the mechanisms that underlie the influence of a cancer cell's microenvironment on its remarkable plasticity and resilience remain incompletely characterized. Ongoing developments in bioengineering promise to advance our capacity to resolve single-cell level changes in response to microenvironment-specific mechanics. While such resolution will surely highlight new therapeutic targets that underlie the burden of metastatic cancer, these studies are principally 
conducted with immortal, commercially available cell lines. While these cell lines have informed cancer biology over many decades, they do not wholly mimic the phenotypic plasticity or responsiveness observed in vivo. Phenotype and behavior may vary more than can be captured by currently available cell lines, thus, idealizing the development of more native, dynamic alternatives. Such developments would further empower metastasis-on-a-chip platforms, facilitating more physiological investigations of the cell-microenvironment interface. Moreover, the prospect of mechanotherapy, such as reversing the ECM remodeling of the TME and surrounding stroma, may prove a beneficial adjunct therapy by improving the efficacy of chemotherapy, thus bettering patient outcomes (Vennin et al., 2018; Tschumperlin and Lagares, 2020). In conducting such research, investigators must acknowledge the mechanosensitivity of metastatic cancers and the mechanical profiles that constitute the metastatic cascade. Here, we highlight the cellular responses to key microenvironmental

\section{REFERENCES}

Aceto, N., Bardia, A., Miyamoto, D. T., Donaldson, M. C., Wittner, B. S., Spencer, J. A., et al. (2014). Circulating tumor cell clusters are oligoclonal precursors of breast cancer metastasis. Cell 158, 1110-1122. doi: 10.1016/j.cell.2014.07.013

Aleman, J., and Skardal, A. (2019). A multi-site metastasis-on-a-chip microphysiological system for assessing metastatic preference of cancer cells. Biotechnol. Bioeng. 116, 936-944. doi: 10.1002/bit.26871

Amschler, K., Erpenbeck, L., Kruss, S., and Schön, M. P. (2014). Nanoscale integrin ligand patterns determine melanoma cell behavior. ACS Nano 8, 9113-9125. doi: $10.1021 / \mathrm{nn} 502690 \mathrm{~b}$

Amschler, K., Kossmann, E., Erpenbeck, L., Kruss, S., Schill, T., Schön, M., et al. (2018). Nanoscale tuning of VCAM-1 determines VLA-4-dependent melanoma cell plasticity on RGD motifs. Mol. Cancer Res. 16, 528-542. doi: 10.1158/15417786.Mcr-17-0272

Au, S. H., Storey, B. D., Moore, J. C., Tang, Q., Chen, Y.-L., Javaid, S., et al. (2016). Clusters of circulating tumor cells traverse capillary-sized vessels. Proc. Natl. Acad. Sci. U.S.A. 113, 4947-4952. doi: 10.1073/pnas.1524448113

Barnes, J. M., Nauseef, J. T., and Henry, M. D. (2012). Resistance to fluid shear stress is a conserved biophysical property of malignant cells. PLoS One 7:e50973. doi: 10.1371/journal.pone.0050973

Beri, P., Popravko, A., Yeoman, B., Kumar, A., Chen, K., Hodzic, E., et al. (2020). Cell adhesiveness serves as a biophysical marker for metastatic potential. Cancer Res. 80, 901-911. doi: 10.1158/0008-5472.Can-19-1794

Bertulli, C., Gerigk, M., Piano, N., Liu, Y., Zhang, D., Müller, T., et al. (2018). Image-assisted microvessel-on-a-chip platform for studying cancer cell transendothelial migration dynamics. Sci. Rep. 8:12480. doi: 10.1038/s41598018-30776-0

Bhatia, S., Wang, P., Toh, A., and Thompson, E. W. (2020). New insights into the role of phenotypic plasticity and EMT in driving cancer progression. Front. Mol. Biosci. 7:71. doi: 10.3389/fmolb.2020.00071

Broders-Bondon, F., Nguyen Ho-Bouldoires, T. H., Fernandez-Sanchez, M.-E., and Farge, E. (2018). Mechanotransduction in tumor progression: the dark side of the force. J. Cell Biol. 217, 1571-1587. doi: 10.1083/jcb.201701039

Chaudhuri, O., Koshy, S. T., Branco da Cunha, C., Shin, J. W., Verbeke, C. S., Allison, K. H., et al. (2014). Extracellular matrix stiffness and composition jointly regulate the induction of malignant phenotypes in mammary epithelium. Nat. Mater. 13, 970-978. doi: 10.1038/nmat 4009

Chen, M. B., Whisler, J. A., Jeon, J. S., and Kamm, R. D. (2013). Mechanisms of tumor cell extravasation in an in vitro microvascular network platform. Integr. Biol. (Camb). 5, 1262-1271. doi: 10.1039/c3ib40149a

Chiang, S. P., Cabrera, R. M., and Segall, J. E. (2016). Tumor cell intravasation. Am. J. Physiol. Cell Physiol. 311, C1-C14. doi: 10.1152/ajpcell.00238.2015 stimuli that corroborate metastasis and represent future therapeutic targets.

\section{AUTHOR CONTRIBUTIONS}

SA reviewed the literature, prepared the figure, and wrote the manuscript. YC edited and supervised the manuscript. Both authors approved the manuscript for publication.

\section{FUNDING}

This work was supported by a Hackett Postgraduate Research Scholarship and an Australian Government Research Training Program Scholarship at The University of Western Australia (to SA) and a Heart Foundation Future Leader Fellowship 101173 (to YC).

Chivukula, V. K., Krog, B. L., Nauseef, J. T., Henry, M. D., and Vigmostad, S. C. (2015). Alterations in cancer cell mechanical properties after fluid shear stress exposure: a micropipette aspiration study. Cell Health Cytoskel. 7, 25-35. doi: 10.2147/CHC.S71852

Denais, C. M., Gilbert, R. M., Isermann, P., McGregor, A. L., te Lindert, M., Weigelin, B., et al. (2016). Nuclear envelope rupture and repair during cancer cell migration. Science 352, 353-358. doi: 10.1126/science.aad7297

Elosegui-Artola, A., Andreu, I., Beedle, A. E. M., Lezamiz, A., Uroz, M., Kosmalska, A. J., et al. (2017). Force triggers YAP nuclear entry by regulating transport across nuclear pores. Cell 171, 1397-1410.e14. doi: 10.1016/j.cell.2017.10.008

Eyckmans, J., Boudou, T., Yu, X., and Chen, C. S. (2011). A hitchhiker's guide to mechanobiology. Dev. Cell 21, 35-47. doi: 10.1016/j.devcel.2011.06.015

Fan, R., Emery, T., Zhang, Y., Xia, Y., Sun, J., and Wan, J. (2016). Circulatory shear flow alters the viability and proliferation of circulating colon cancer cells. Sci. Rep. 6, 27073. doi: 10.1038/srep27073

Follain, G., Herrmann, D., Harlepp, S., Hyenne, V., Osmani, N., Warren, S. C., et al. (2020). Fluids and their mechanics in tumour transit: shaping metastasis. Nat. Rev. Cancer 20, 107-124. doi: 10.1038/s41568-019-0221-x

Frisch, S. M., and Screaton, R. A. (2001). Anoikis mechanisms. Curr. Opin. Cell Biol. 13, 555-562. doi: 10.1016/S0955-0674(00)00251-9

Fu, Y., Chin, L. K., Bourouina, T., Liu, A. Q., and VanDongen, A. M. (2012). Nuclear deformation during breast cancer cell transmigration. Lab. Chip 12, 3774-3778. doi: 10.1039/c2lc40477j

Guadamillas, M. C., Cerezo, A., and del Pozo, M. A. (2011). Overcoming anoikis pathways to anchorage-independent growth in cancer. J. Cell Sci. 124, 31893197. doi: $10.1242 /$ jcs. 072165

Guck, J., Schinkinger, S., Lincoln, B., Wottawah, F., Ebert, S., Romeyke, M., et al. (2005). Optical deformability as an inherent cell marker for testing malignant transformation and metastatic competence. Biophys. J. 88, 3689-3698. doi: 10. 1529/biophysj.104.045476

Han, Y. L., Pegoraro, A. F., Li, H., Li, K., Yuan, Y., Xu, G., et al. (2020). Cell swelling, softening and invasion in a three-dimensional breast cancer model. Nat. Phys. 16, 101-108. doi: 10.1038/s41567-019-0680-8

Hanahan, D., and Weinberg, R. A. (2011). Hallmarks of cancer: the next generation. Cell 144, 646-674. doi: 10.1016/j.cell.2011.02.013

Hassell, B. A., Goyal, G., Lee, E., Sontheimer-Phelps, A., Levy, O., Chen, C. S., et al. (2017). Human organ chip models recapitulate orthotopic lung cancer growth, therapeutic responses, and tumor dormancy in vitro. Cell Rep. 21, 508-516. doi: 10.1016/j.celrep.2017.09.043

Heo, S.-J., Song, K., Thakur, S., Miller, L., Cao, X., Peredo, A., et al. (2020). Nuclear softening expedites interstitial cell migration in fibrous networks and dense connective tissues. Sci. Adv. 6, eaax5083. doi: 10.1126/sciadv.aax5083

Herráez-Aguilar, D., Madrazo, E., Lopez Menendez, H., Ramirez, M., Monroy, F., and Redondo-Munoz, J. (2020). Multiple particle tracking analysis in isolated 
nuclei reveals the mechanical phenotype of leukemia cells. Sci. Rep. 10, 6707. doi: 10.1038/s41598-020-63682-5

Holenstein, C. N., Horvath, A., Schär, B., Schoenenberger, A. D., Bollhalder, M., Goedecke, N., et al. (2019). The relationship between metastatic potential and in vitro mechanical properties of osteosarcoma cells. Mol. Biol. Cell 30, 887-898. doi: $10.1091 / \mathrm{mbc} . \mathrm{E} 18-08-0545$

Holle, A. W., Govindan Kutty Devi, N., Clar, K., Fan, A., Saif, T., Kemkemer, R., et al. (2019). Cancer cells invade confined microchannels via a self-directed mesenchymal-to-amoeboid transition. Nano Lett. 19, 2280-2290. doi: 10.1021/ acs.nanolett.8b04720

Holle, A. W., Young, J. L., Van Vliet, K. J., Kamm, R. D., Discher, D., Janmey, P., et al. (2018). Cell-extracellular matrix mechanobiology: forceful tools and emerging needs for basic and translational research. Nano Lett. 18, 1-8. doi: 10.1021/acs.nanolett.7b04982

Horzum, U., Ozdil, B., and Pesen-Okvur, D. (2015). Differentiation of normal and cancer cell adhesion on custom designed protein nanopatterns. Nano Lett. 15, 5393-5403. doi: 10.1021/acs.nanolett.5b01785

Hoshino, A., Costa-Silva, B., Shen, T.-L., Rodrigues, G., Hashimoto, A., Tesic Mark, M., et al. (2015). Tumour exosome integrins determine organotropic metastasis. Nature 527, 329-335. doi: 10.1038/nature15756

Huang, Y. L., Shiau, C., Wu, C., Segall, J. E., and Wu, M. (2020). The architecture of co-culture spheroids regulates tumor invasion within a 3D extracellular matrix. Biophys. Rev. Lett. 15, 131-141. doi: 10.1142/s1793048020500034

Jang, I., and Beningo, K. A. (2019). Integrins. CAFs and mechanical forces in the progression of cancer. Cancers 11:721. doi: 10.3390/cancers11050721

Jeon, J. S., Bersini, S., Gilardi, M., Dubini, G., Charest, J. L., Moretti, M., et al. (2015). Human 3D vascularized organotypic microfluidic assays to study breast cancer cell extravasation. Proc. Natl. Acad. Sci. U.S.A. 112, 214-219. doi: 10. 1073/pnas.1417115112

Jeon, J. S., Zervantonakis, I. K., Chung, S., Kamm, R. D., and Charest, J. L. (2013). In vitro model of tumor cell extravasation. PLoS One 8:e56910. doi: 10.1371/ journal.pone.0056910

Joyce, M. H., Lu, C., James, E. R., Hegab, R., Allen, S. C., Suggs, L. J., et al. (2018). Phenotypic basis for matrix stiffness-dependent chemoresistance of breast cancer cells to doxorubicin. Front. Oncol. 8:337. doi: 10.3389/fonc.2018.00337

Kaukonen, R., Mai, A., Georgiadou, M., Saari, M., De Franceschi, N., Betz, T., et al. (2016). Normal stroma suppresses cancer cell proliferation via mechanosensitive regulation of JMJD1a-mediated transcription. Nat. Commun. 7:12237. doi: $10.1038 /$ ncomms12237

Khan, Z. S., Santos, J. M., and Hussain, F. (2018). Aggressive prostate cancer cell nuclei have reduced stiffness. Biomicrofluidics 12:014102. doi: 10.1063/1. 5019728

Kim, C., Young, J. L., Holle, A. W., Jeong, K., Major, L. G., Jeong, J. H., et al. (2020). Stem cell mechanosensation on gelatin methacryloyl (GelMA) stiffness gradient hydrogels. Ann. Biomed. Eng. 48, 893-902. doi: 10.1007/s10439-019-02428-5

Kim, J., and Bae, J. S. (2016). Tumor-associated macrophages and neutrophils in tumor microenvironment. Mediators Inflamm. 2016, 6058147. doi: 10.1155/ 2016/6058147

Kim, J., Lee, C., Kim, I., Ro, J., Kim, J., Min, Y., et al. (2020). Three-dimensional human liver-chip emulating premetastatic niche formation by breast cancerderived extracellular vesicles. ACS Nano 14, 14971-14988. doi: 10.1021/ acsnano.0c04778

Kirby, T. J., and Lammerding, J. (2018). Emerging views of the nucleus as a cellular mechanosensor. Nat. Cell Biol. 20, 373-381. doi: 10.1038/s41556-018-0038-y

Kosla, J., Paňková, D., Plachý, J., Tolde, O., Bicanová, K., Dvořák, M., et al. (2013). Metastasis of aggressive amoeboid sarcoma cells is dependent on Rho/ROCK/MLC signaling. Cell Commun. Signal. 11:51. doi: 10.1186/1478811X-11-51

Kristal-Muscal, R., Dvir, L., and Weihs, D. (2013). Metastatic cancer cells tenaciously indent impenetrable, soft substrates. New J. Phys. 15:035022. doi: $10.1088 / 1367-2630 / 15 / 3 / 035022$

Kuen, J., Darowski, D., Kluge, T., and Majety, M. (2017). Pancreatic cancer cell/fibroblast co-culture induces M2 like macrophages that influence therapeutic response in a 3D model. PLoS One 12:e0182039. doi: 10.1371/ journal.pone.0182039

Kühlbach, C., da Luz, S., Baganz, F., Hass, V. C., and Mueller, M. M. (2018). A microfluidic system for the investigation of tumor cell extravasation. Bioeng. (Basel) 5:40. doi: 10.3390/bioengineering5020040
Lee, H., Jang, Y., Seo, J., Nam, J.-M., and Char, K. (2011). Nanoparticlefunctionalized polymer platform for controlling metastatic cancer cell adhesion, shape, and motility. ACS Nano 5, 5444-5456. doi: 10.1021/nn202103z

Lee, H., Park, W., Ryu, H., and Jeon, N. L. (2014). A microfluidic platform for quantitative analysis of cancer angiogenesis and intravasation. Biomicrofluidics 8:054102. doi: 10.1063/1.4894595

Lee, H. J., Diaz, M. F., Price, K. M., Ozuna, J. A., Zhang, S., Sevick-Muraca, E. M., et al. (2017). Fluid shear stress activates YAP1 to promote cancer cell motility. Nat. Commun. 8:14122. doi: 10.1038/ncomms 14122

Lee, H. J., Ewere, A., Diaz, M. F., and Wenzel, P. L. (2018). TAZ responds to fluid shear stress to regulate the cell cycle. Cell Cycle 17, 147-153. doi: 10.1080/ 15384101.2017.1404209

Lee, J. Y., Chang, J. K., Dominguez, A. A., Lee, H.-P., Nam, S., Chang, J., et al. (2019). YAP-independent mechanotransduction drives breast cancer progression. Nat. Commun. 10:1848. doi: 10.1038/s41467-019-09755-0

Levental, K. R., Yu, H., Kass, L., Lakins, J. N., Egeblad, M., Erler, J. T., et al. (2009). Matrix crosslinking forces tumor progression by enhancing integrin signaling. Cell 139, 891-906. doi: 10.1016/j.cell.2009.10.027

Li, S., Chen, Y., Zhang, Y., Jiang, X., Jiang, Y., Qin, X., et al. (2019). Shear stress promotes anoikis resistance of cancer cells via caveolin-1-dependent extrinsic and intrinsic apoptotic pathways. J. Cell. Physiol. 234, 3730-3743. doi: 10.1002/ jcp. 27149

Libring, S., Shinde, A., Chanda, M. K., Nuru, M., George, H., Saleh, A. M., et al. (2020). The dynamic relationship of breast cancer cells and fibroblasts in fibronectin accumulation at primary and metastatic tumor sites. Cancers (Basel) 12, 1270. doi: $10.3390 /$ cancers 12051270

Lomakin, A. J., Cattin, C. J., Cuvelier, D., Alraies, Z., Molina, M., Nader, G. P. F., et al. (2020). The nucleus acts as a ruler tailoring cell responses to spatial constraints. Science 370:eaba2894. doi: 10.1126/science.aba2894

Lugo-Cintrón, K., Gong, M., Ayuso, J. M., Tomko, L., Beebe, D., Virumbrales, M., et al. (2020). Breast fibroblasts and ECM components modulate breast cancer cell migration through the secretion of MMPs in a 3D microfluidic co-culture model. Cancers 12:1173. doi: 10.3390/cancers 12051173

Ma, D., Wang, R., Chen, S., Luo, T., Chow, Y.-T., and Sun, D. (2018). Microfluidic platform for probing cancer cells migration property under periodic mechanical confinement. Biomicrofluidics 12:024118. doi: 10.1063/1.5030135

Ma, S., Fu, A., Chiew, G. G. Y., and Luo, K. Q. (2017). Hemodynamic shear stress stimulates migration and extravasation of tumor cells by elevating cellular oxidative level. Cancer Lett. 388, 239-248. doi: 10.1016/j.canlet.2016.12.001

Mak, M., Reinhart-King, C. A., and Erickson, D. (2013). Elucidating mechanical transition effects of invading cancer cells with a subnucleus-scaled microfluidic serial dimensional modulation device. Lab. Chip 13, 340-348. doi: 10.1039/ c2lc41117b

Marlar, S., Abdellatef, S. A., and Nakanishi, J. (2016). Reduced adhesive ligand density in engineered extracellular matrices induces an epithelialmesenchymal-like transition. Acta Biomater. 39, 106-113. doi: 10.1016/j.actbio. 2016.05.006

Mierke, C. T. (2019). The matrix environmental and cell mechanical properties regulate cell migration and contribute to the invasive phenotype of cancer cells. Rep. Prog. Phys. 82:064602. doi: 10.1088/1361-6633/ ab1628

Mosier, J. A., Rahman-Zaman, A., Zanotelli, M. R., VanderBurgh, J. A., Bordeleau, F., Hoffman, B. D., et al. (2019). Extent of cell confinement in microtracks affects speed and results in differential matrix strains. Biophys. J. 117, 1692-1701. doi: 10.1016/j.bpj.2019.09.024

Nader, G., Aguera-Gonzalez, S., Routet, F., Gratia, M., Maurin, M., Cancila, V., et al. (2020). Compromised nuclear envelope integrity drives tumor cell invasion. bioRxiv [Preprint]. doi: 10.1101/2020.05.22.110122.

Nashimoto, Y., Okada, R., Hanada, S., Arima, Y., Nishiyama, K., Miura, T., et al. (2020). Vascularized cancer on a chip: the effect of perfusion on growth and drug delivery of tumor spheroid. Biomaterials 229:119547. doi: 10.1016/j. biomaterials.2019.119547

Nguyen, D. T., Lee, E., Alimperti, S., Norgard, R. J., Wong, A., Lee, J. J., et al. (2019). A biomimetic pancreatic cancer on-chip reveals endothelial ablation via ALK7 signaling. Sci. Adv. 5:eaav6789. doi: 10.1126/sciadv.aav6789

Nguyen, D. X., Bos, P. D., and Massagué, J. (2009). Metastasis: from dissemination to organ-specific colonization. Nat. Rev. Cancer 9, 274-284. doi: 10.1038/ $\operatorname{nrc} 2622$ 
Novak, C. M., Horst, E. N., Taylor, C. C., Liu, C. Z., and Mehta, G. (2019). Fluid shear stress stimulates breast cancer cells to display invasive and chemoresistant phenotypes while upregulating PLAU in a 3D bioreactor. Biotechnol. Bioeng. 116, 3084-3097. doi: 10.1002/bit.27119

Ondeck, M. G., Kumar, A., Placone, J. K., Plunkett, C. M., Matte, B. F., Wong, K. C., et al. (2019). Dynamically stiffened matrix promotes malignant transformation of mammary epithelial cells via collective mechanical signaling. Proc. Natl. Acad. Sci. U.S.A. 116, 3502-3507. doi: 10.1073/pnas.1814204116

Otto, O., Rosendahl, P., Mietke, A., Golfier, S., Herold, C., Klaue, D., et al. (2015). Real-time deformability cytometry: on-the-fly cell mechanical phenotyping. Nat. Methods 12, 199-202. doi: 10.1038/nmeth.3281

Palacio-Castaneda, V., Kooijman, L., Venzac, B., Verdurmen, W., and Gac, S. (2020). Metabolic switching of tumor cells under hypoxic conditions in a tumor-on-a-chip model. Micromachines 11:382. doi: 10.3390/mi11040382

Panciera, T., Citron, A., Di Biagio, D., Battilana, G., Gandin, A., Giulitti, S., et al. (2020). Reprogramming normal cells into tumour precursors requires ECM stiffness and oncogene-mediated changes of cell mechanical properties. Nat. Mater. 19, 797-806. doi: 10.1038/s41563-020-0615-x

Paoli, P., Giannoni, E., and Chiarugi, P. (2013). Anoikis molecular pathways and its role in cancer progression. Biochim. Biophys. Acta 1833, 3481-3498. doi: 10.1016/j.bbamcr.2013.06.026

Peela, N., Sam, F. S., Christenson, W., Truong, D., Watson, A. W., Mouneimne, G., et al. (2016). A three dimensional micropatterned tumor model for breast cancer cell migration studies. Biomaterials 81, 72-83. doi: 10.1016/j. biomaterials.2015.11.039

Peng, F., Setyawati, M. I., Tee, J. K., Ding, X., Wang, J., Nga, M. E., et al. (2019). Nanoparticles promote in vivo breast cancer cell intravasation and extravasation by inducing endothelial leakiness. Nat. Nanotechnol. 14, 279-286. doi: 10.1038/s41565-018-0356-Z

Plaster, M., Singh, S., and Tavana, H. (2019). Fibroblasts promote proliferation and matrix invasion of breast cancer cells in co-culture models. Adv. Ther. 2:1900121. doi: 10.1002/adtp.201900121

Plodinec, M., Loparic, M., Monnier, C. A., Obermann, E. C., Zanetti-Dallenbach, R., Oertle, P., et al. (2012). The nanomechanical signature of breast cancer. Nat. Nanotechnol. 7, 757-765. doi: 10.1038/nnano.2012.167

Raab, M., Gentili, M., de Belly, H., Thiam, H.-R., Vargas, P., Jimenez, A. J., et al. (2016). ESCRT III repairs nuclear envelope ruptures during cell migration to limit DNA damage and cell death. Science 352, 359-362. doi: 10.1126/science. aad7611

Rajan, S. A. P., Aleman, J., Wan, M., Pourhabibi Zarandi, N., Nzou, G., Murphy, S., et al. (2020a). Probing prodrug metabolism and reciprocal toxicity with an integrated and humanized multi-tissue organ-on-a-chip platform. Acta Biomater. 106, 124-135. doi: 10.1016/j.actbio.2020.02.015

Rajan, S. A. P., Skardal, A., and Hall, A. R. (2020b). Multi-domain photopatterned $3 \mathrm{D}$ tumor constructs in a micro-physiological system for analysis. Quantification, and isolation of infiltrating cells. Adv. Biosyst. 4:1900273. doi: 10.1002/adbi.201900273

Redfern, A., Agarwal, V., and Thompson, E. W. (2019). Hypoxia as a signal for prison breakout in cancer. Curr. Opin. Clin. Nutr. Metab. Care 22, 250-263. doi: $10.1097 / \mathrm{mco} .0000000000000577$

Reversat, A., Gaertner, F., Merrin, J., Stopp, J., Tasciyan, S., Aguilera, J., et al. (2020). Cellular locomotion using environmental topography. Nature 582, 582-585. doi: 10.1038/s41586-020-2283-z

Rice, A. J., Cortes, E., Lachowski, D., Cheung, B. C. H., Karim, S. A., Morton, J. P., et al. (2017). Matrix stiffness induces epithelial-mesenchymal transition and promotes chemoresistance in pancreatic cancer cells. Oncogenesis 6:e352. doi: 10.1038/oncsis.2017.54

Roh-Johnson, M., Bravo-Cordero, J. J., Patsialou, A., Sharma, V. P., Guo, P., Liu, H., et al. (2014). Macrophage contact induces RhoA GTPase signaling to trigger tumor cell intravasation. Oncogene 33, 4203-4212. doi: 10.1038/onc.2013.377

Sfriso, R., Zhang, S., Bichsel, C. A., Steck, O., Despont, A., Guenat, O. T., et al. (2018). 3D artificial round section micro-vessels to investigate endothelial cells under physiological flow conditions. Sci. Rep. 8:5898. doi: 10.1038/s41598-01824273-7

Sharifi, F., Yesil-Celiktas, O., Kazan, A., Maharjan, S., Saghazadeh, S., Firoozbakhsh, K., et al. (2020). A hepatocellular carcinoma-bone metastasison-a-chip model for studying thymoquinone-loaded anticancer nanoparticles. Bio Design Manuf. 3, 189-202. doi: 10.1007/s42242-020-00074-8
Sima, F., Kawano, H., Hirano, M., Miyawaki, A., Obata, K., Serien, D., et al. (2020). Mimicking intravasation-extravasation with a 3D glass nanofluidic model for the chemotaxis-free migration of cancer cells in confined spaces. Adv. Mater. Technol. 5:2000484. doi: 10.1002/admt.202000484

Skardal, A., Devarasetty, M., Forsythe, S., Atala, A., and Soker, S. (2016). A reductionist metastasis-on-a-chip platform for in vitro tumor progression modeling and drug screening. Biotechnol. Bioeng. 113, 2020-2032. doi: 10.1002/ bit. 25950

Sleeboom, J. J. F., Eslami Amirabadi, H., Nair, P., Sahlgren, C. M., and den Toonder, J. M. J. (2018). Metastasis in context: modeling the tumor microenvironment with cancer-on-a-chip approaches. Dis. Model. Mech. 11:dmm033100. doi: 10. 1242/dmm.033100

Sontheimer-Phelps, A., Hassell, B. A., and Ingber, D. E. (2019). Modelling cancer in microfluidic human organs-on-chips. Nat. Rev. Cancer 19, 65-81. doi: 10.1038/ s41568-018-0104-6

Swaminathan, V., Mythreye, K., O’Brien, E. T., Berchuck, A., Blobe, G. C., and Superfine, R. (2011). Mechanical stiffness grades metastatic potential in patient tumor cells and in cancer cell lines. Cancer Res. 71, 5075-5080. doi: 10.1158/ 0008-5472.Can-11-0247

Tang, K., Li, S., Li, P., Xia, Q., Yang, R., Li, T., et al. (2020). Shear stress stimulates integrin $\beta 1$ trafficking and increases directional migration of cancer cells via promoting deacetylation of microtubules. Biochim. Biophys. Acta Mol. Cell Res. 1867:118676. doi: 10.1016/j.bbamcr.2020.118676

Tian, F., Lin, T.-C., Wang, L., Chen, S., Chen, X., Yiu, P. M., et al. (2020). Mechanical responses of breast cancer cells to substrates of varying stiffness revealed by single-cell measurements. J. Phys. Chem. Lett. 11, 7643-7649. doi: 10.1021/acs.jpclett.0c02065

Tschumperlin, D. J., and Lagares, D. (2020). Mechano-therapeutics: targeting mechanical signaling in fibrosis and tumor stroma. Pharmacol. Ther. 212:107575. doi: $10.1016 /$ j.pharmthera.2020.107575

Tse, J. M., Cheng, G., Tyrrell, J. A., Wilcox-Adelman, S. A., Boucher, Y., Jain, R. K., et al. (2012). Mechanical compression drives cancer cells toward invasive phenotype. Proc. Natl. Acad. Sci. U.S.A. 109, 911-916. doi: 10.1073/pnas. 1118910109

Vennin, C., Mélénec, P., Rouet, R., Nobis, M., Cazet, A. S., Murphy, K. J., et al. (2019). CAF hierarchy driven by pancreatic cancer cell p53-status creates a pro-metastatic and chemoresistant environment via perlecan. Nat. Commun. 10:3637. doi: 10.1038/s41467-019-10968-6

Vennin, C., Murphy, K. J., Morton, J. P., Cox, T. R., Pajic, M., and Timpson, P. (2018). Reshaping the tumor stroma for treatment of pancreatic cancer. Gastroenterology 154, 820-838. doi: 10.1053/j.gastro.2017.11.280

Venturini, V., Pezzano, F., Català Castro, F., Häkkinen, H.-M., Jiménez-Delgado, S., Colomer-Rosell, M., et al. (2020). The nucleus measures shape changes for cellular proprioception to control dynamic cell behavior. Science 370:eaba2644. doi: 10.1126/science.aba2644

Wallez, Y., and Huber, P. (2008). Endothelial adherens and tight junctions in vascular homeostasis, inflammation and angiogenesis. Biochim. Biophys. Acta 1778, 794-809. doi: 10.1016/j.bbamem.2007.09.003

Wang, C., Baker, B. M., Chen, C. S., and Schwartz, M. A. (2013). Endothelial cell sensing of flow direction. Arterioscler. Thromb. Vasc. Biol. 33, 2130-2136. doi: 10.1161/ATVBAHA.113.301826

Wang, M., Cheng, B., Yang, Y., Liu, H., Huang, G., Han, L., et al. (2019). Microchannel stiffness and confinement jointly induce the mesenchymalamoeboid transition of cancer cell migration. Nano Lett. 19, 5949-5958. doi: 10.1021/acs.nanolett.9b01597

Wei, S. C., Fattet, L., Tsai, J. H., Guo, Y., Pai, V. H., Majeski, H. E., et al. (2015). Matrix stiffness drives epithelial-mesenchymal transition and tumour metastasis through a TWIST1-G3BP2 mechanotransduction pathway. Nat. Cell Biol. 17, 678-688. doi: 10.1038/ncb3157

Weigelin, B., Bakker, G. J., and Friedl, P. (2012). Intravital third harmonic generation microscopy of collective melanoma cell invasion: principles of interface guidance and microvesicle dynamics. Intravital 1, 32-43. doi: 10.4161/ intv. 21223

Wisdom, K. M., Adebowale, K., Chang, J., Lee, J. Y., Nam, S., Desai, R., et al. (2018). Matrix mechanical plasticity regulates cancer cell migration through confining microenvironments. Nat. Commun. 9:4144. doi: 10.1038/s41467-018-06641-z

World Health Organisation (2018). Cancer [Online]. Available online at: https: //www.who.int/news-room/fact-sheets/detail/cancer (accessed June 3, 2020) 
Wullkopf, L., West, A.-K. V., Leijnse, N., Cox, T. R., Madsen, C. D., Oddershede, L. B., et al. (2018). Cancer cells' ability to mechanically adjust to extracellular matrix stiffness correlates with their invasive potential. Mol. Biol. Cell 29, 2378-2385. doi: 10.1091/mbc.E18-05-0319

Yamauchi, M., Gibbons, D. L., Zong, C., Fradette, J. J., Bota-Rabassedas, N., and Kurie, J. M. (2020). Fibroblast heterogeneity and its impact on extracellular matrix and immune landscape remodeling in cancer. Matrix Biol. 91-92, 8-18. doi: 10.1016/j.matbio.2020.05.001

Yang, H., Guan, L., Li, S., Jiang, Y., Xiong, N., Li, L., et al. (2016). Mechanosensitive caveolin-1 activation-induced PI3K/Akt/mTOR signaling pathway promotes breast cancer motility, invadopodia formation and metastasis in vivo. Oncotarget 7, 16227-16247. doi: 10.18632/oncotarget.7583

Young, J. L., Hua, X., Somsel, H., Reichart, F., Kessler, H., and Spatz, J. P. (2020). Integrin subtypes and nanoscale ligand presentation influence drug sensitivity in cancer cells. Nano Lett. 20, 1183-1191. doi: 10.1021/acs.nanolett.9b04607

Yu, M., Bardia, A., Wittner, B. S., Stott, S. L., Smas, M. E., Ting, D. T., et al. (2013). Circulating breast tumor cells exhibit dynamic changes in epithelial and mesenchymal composition. Science 339, 580-584. doi: 10.1126/science.1228522

Zavyalova, M. V., Denisov, E. V., Tashireva, L. A., Savelieva, O. E., Kaigorodova, E. V., Krakhmal, N. V., et al. (2019). Intravasation as a key step in cancer metastasis. Biochem. (Mosc). 84, 762-772. doi: 10.1134/S0006297919070071

Zervantonakis, I. K., Hughes-Alford, S. K., Charest, J. L., Condeelis, J. S., Gertler, F. B., and Kamm, R. D. (2012). Three-dimensional microfluidic model for tumor cell intravasation and endothelial barrier function. Proc. Natl. Acad. Sci. U.S.A. 109, 13515-13520. doi: 10.1073/pnas.1210182109

Zhang, W., Lee, W. Y., Siegel, D. S., Tolias, P., and Zilberberg, J. (2014). Patientspecific 3D microfluidic tissue model for multiple myeloma. Tissue Eng. Part C Methods 20, 663-670. doi: 10.1089/ten.TEC.2013.0490

Zhang, X., Yang, L., Chien, S., and Lv, Y. (2018). Suspension state promotes metastasis of breast cancer cells by up-regulating cyclooxygenase- 2 . Theranostics 8, 3722-3736. doi: 10.7150/thno.25434

Zhao, F., Li, L., Guan, L., Yang, H., Wu, C., and Liu, Y. (2014). Roles for GP IIb/IIIa and $\alpha v \beta 3$ integrins in MDA-MB-231 cell invasion and shear flow-induced cancer cell mechanotransduction. Cancer Lett. 344, 62-73. doi: 10.1016/j.canlet. 2013.10.019

Conflict of Interest: The authors declare that the research was conducted in the absence of any commercial or financial relationships that could be construed as a potential conflict of interest.

Copyright (c) 2021 Amos and Choi. This is an open-access article distributed under the terms of the Creative Commons Attribution License (CC BY). The use, distribution or reproduction in other forums is permitted, provided the original author(s) and the copyright owner(s) are credited and that the original publication in this journal is cited, in accordance with accepted academic practice. No use, distribution or reproduction is permitted which does not comply with these terms. 